\title{
EDUCATION AND TRAINING Recognising the elephant in the room: Foundation doctors and anticipatory care planning
}

\author{
Authors: Helen Chapman, ${ }^{A}$ Miriam Jassam, ${ }^{A}$ Rebecca O'Rourke ${ }^{B}$ and Rebecca Anthony ${ }^{C}$
}

Anticipatory/advance care planning (ACP) conversations are often known to be challenging and should be undertaken sensitively. A qualitative service evaluation was undertaken with the elderly care department at The Leeds Teaching Hospitals NHS Trust by medical students to explore the thoughts and experiences of foundation doctors. ACP discussions include consideration of future treatment options and preferences; however, foundation doctors were not confident to discuss issues beyond resuscitation status. The key themes identified include understanding of and confidence in ACP, variation across specialty and medical educational needs. The analysis highlights a further need for qualitative research into prevalent attitudes towards ACP discussions across the range of specialties.

KEYWORDS: junior doctors, DNACPR, anticipatory care planning, medical education

DOI: $10.7861 /$ fhj.2020-0200

\section{Background}

Anticipatory care planning (ACP; also known as advance care planning) is an overarching term which covers a broad range of medical treatments and care preferences including, but not limited to, do not attempt cardiopulmonary resuscitation (DNACPR). ACP also includes discussions regarding the patients' long-term preferences and future wishes (such as place of future care and views on invasive treatment options). These discussions help clinicians direct the focus of care in line with the patients' expressed wishes, should deterioration and incapacity occur.

ACP conversations are recommended to be tailored to the individual situation where often a junior doctor will be the patient's familiar point of contact. ${ }^{1}$ ACP discussions can be challenging, and they should be handled sensitively. They require a degree of skill, training and good communication skills to undertake effectively. These conversations are notoriously challenging for newly-qualified foundation doctors, and a

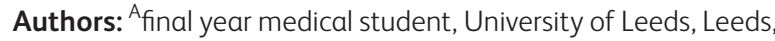
UK; ${ }^{B}$ principal teaching fellow, University of Leeds, Leeds, UK;

${ }^{C}$ consultant in elderly medicine, The Leeds Teaching Hospitals NHS Trust, Leeds, UK recent quality improvement project demonstrated clear benefit in a workplace-based training intervention. ${ }^{2}$ In this project, foundation doctors observed a senior undertake an initial ACP discussion, then arranged to meet the patient and their family for a second conversation in the days following. This is in keeping with recommendations for best practice in utilising a series of conversations, rather than an isolated discussion, as this allows for clarification. ${ }^{3}$ The reflection following the interaction revealed that junior doctors felt empowered to undertake further ACP with increased competence and greater confidence. ${ }^{2}$

The Recommended Summary Plan for Emergency Care and Treatment (ReSPECT) form has been nationally adopted to unify and simplify the recording of ACP decision-making discussions across the NHS. ${ }^{4}$ The ReSPECT form aims to encourage personcentred care by identifying goals of treatments (palliation or life prolonging focus) and priorities, in the event of an emergency presentation. This may include escalation decisions and location of care, as well as a recommendation regarding resuscitation.

Furthermore, the Royal College of Physicians recommend prioritising the training of undergraduate and postgraduate physicians to hold future planning conversations and consider their importance as equal to physical interventions. ${ }^{5}$

\section{Method}

As part of a research project, we undertook a service evaluation with The Leeds Teaching Hospitals NHS Trust care of the elderly department during years 4 and 5 of the MBChB. The project applied a semi-structured interviewing method for data collection, which included two pilot interviews in order to develop the question stems. Table 1 shows the key question stems and expanding themes utilised in each interview.

Eight foundation year-2 (FY2) doctors were voluntarily recruited by the researchers during their second job rotation. The interviews were held during the participants' working day in a private environment lasting approximately 30 minutes.

The interviews were digitally recorded with the consent of each participant, and manually transcribed by each interviewer. Subsequently, thematic analysis was undertaken with triangulation of two transcripts between researchers, and a third with a qualitative methods supervisor.

\section{Results}

The perspective of the foundation doctors interviewed highlighted a discrepancy between the reality of some unexpected end-of- 
Table 1. Semi-structured interview question stems

\begin{tabular}{|c|c|c|}
\hline $\begin{array}{l}\text { Stem } \\
\text { number }\end{array}$ & Question stem & Expanding themes \\
\hline \multirow[t]{2}{*}{ I } & \multirow{2}{*}{$\begin{array}{l}\text { What do you } \\
\text { understand by } \\
\text { anticipatory care } \\
\text { planning? }\end{array}$} & $\begin{array}{l}\text { Have you had teaching at } \\
\text { medical school or during } \\
\text { foundation training? }\end{array}$ \\
\hline & & $\begin{array}{l}\text { How does it impact on patient } \\
\text { care? }\end{array}$ \\
\hline \multirow[t]{7}{*}{ II } & \multirow{7}{*}{$\begin{array}{l}\text { What witnessed } \\
\text { experiences } \\
\text { have you had of } \\
\text { anticipatory care } \\
\text { planning? }\end{array}$} & $\begin{array}{l}\text { Are you included in these } \\
\text { discussions? }\end{array}$ \\
\hline & & Where did they take place? \\
\hline & & $\begin{array}{l}\text { Did you feel it was an } \\
\text { appropriate setting? }\end{array}$ \\
\hline & & Is your input encouraged? \\
\hline & & $\begin{array}{l}\text { Who initiates these } \\
\text { conversations: families or } \\
\text { doctors? }\end{array}$ \\
\hline & & $\begin{array}{l}\text { Why were they positive or } \\
\text { negative? }\end{array}$ \\
\hline & & $\begin{array}{l}\text { Were there disagreements or } \\
\text { difficulties from family or staff? }\end{array}$ \\
\hline \multirow[t]{5}{*}{ III } & \multirow{5}{*}{$\begin{array}{l}\text { What personal } \\
\text { experience have } \\
\text { you had in having } \\
\text { these conversations } \\
\text { with patients and } \\
\text { their families? }\end{array}$} & $\begin{array}{l}\text { Is it a part of your role; should } \\
\text { it be? }\end{array}$ \\
\hline & & Is your input encouraged? \\
\hline & & How did you feel? \\
\hline & & $\begin{array}{l}\text { Have you witnessed or } \\
\text { have you been involved in } \\
\text { futile resuscitation, where } \\
\text { anticipatory care planning has } \\
\text { not occurred? }\end{array}$ \\
\hline & & $\begin{array}{l}\text { What effect did this have on } \\
\text { you? }\end{array}$ \\
\hline \multirow[t]{3}{*}{ IV } & \multirow{3}{*}{$\begin{array}{l}\text { Do you feel } \\
\text { confident having } \\
\text { these discussions? }\end{array}$} & Why / why not? \\
\hline & & $\begin{array}{l}\text { What could be offered to you } \\
\text { to increase this? }\end{array}$ \\
\hline & & $\begin{array}{l}\text { What do you think are the } \\
\text { main barriers? }\end{array}$ \\
\hline
\end{tabular}

life care situations and their perceived scope of practice. These conversations are reported to occur outside of the consultantled ward round and fall to junior members of the team. The participants undertook ACP conversations at the request of a senior for a variety of reasons including practicalities (presence on the ward), having a rapport with the family and within the framework of developing communication skills. Thematic analysis revealed three main areas: understanding of and confidence in ACP, variation in specialty and further educational needs (Table 2).

\section{Theme A: Understanding of and confidence in ACP}

All foundation doctors felt that DNACPR discussions were vital and had a positive impact on patient care (question stem I). Seven of the eight participants reported that they lacked confidence holding DNACPR discussions upon graduation; however, all participants felt that they had gained confidence by FY2 (question stem IV). In addition, previous inappropriate resuscitation attempts had acted as a significant driver for future ACP conversations and increased confidence (question stem III). All eight foundation doctors framed their answers solely on DNACPR decisions throughout the interview. Moreover, seven foundation doctors felt that they lacked the experience to hold ACP discussions broader than DNACPR (question stem IV). The rationale given included prognostic uncertainty, lacking technical experience or starting a new rotation.

\section{Theme B: Variation in specialty}

The expectations of foundation doctors vary to some extent depending on rotation. All the participants felt it was within their remit to undertake ACP discussions when clearly delegated or instructed to do so by a senior (question stem III). All participants recognised the importance of holding ACP discussions early, however, four explicitly cited delays and an absence of these taking place on surgical wards (question stem II). Differing senior opinions caused ambiguity as cited by three participants (question stem II and III).

One participant with oncology experience stated that they were rarely invited to observe the detailed ACP conversations with seniors. Three participants completed care of the elderly rotations within FY1 and reported greater confidence DNACPR discussions. These participants stated that ACP and DNACPR were routinely prioritised within the patient's care in comparison with other specialties.

\section{Theme C: Further educational needs}

All foundation doctors reported that, although medical school teaching had covered the basics of end-of-life care and DNACPR, there was distinct lack of teaching of ACP. Three interviewees specifically mentioned sessions on DNACPR with an absence of ACP. One participant specifically mentioned a lack of guidance on how to initiate these conversations (question stem I). All requested greater support to develop these skills.

Only two participants lacked clarity about who can make these decisions and at what level, with the majority feeling it should be delegated by a senior clinician (question stem I). All believed the skillset of undertaking ACP conversations is developed best through practical learning experiences, and that supportive senior staff are paramount to this development (question stem IV).

\section{Discussion}

\section{Should foundation doctors go beyond DNACPR?}

Theme A suggests foundation doctors have greater confidence with DNACPR discussions than ACP as demonstrated by framing their responses specifically to resuscitation. Foundation doctors are more experienced with advance life support, both in practice and in formal training. The importance of offering the protection of a DNACPR to the frail population is well understood by foundation doctors. The attitude of the participants is in keeping with the original aims of a documented DNACPR decision, designed to protect people who would not benefit from CPR when dying. ${ }^{6}$

Furthermore, the importance of in-depth ACP was well understood by foundation doctors, yet all felt the complexity of guiding these decisions well beyond their abilities. Use of 
Table 2. Themes and interview quotations

\author{
Theme A: Understanding of and confidence \\ in anticipatory care planning \\ Doctor 5: 'Resuscitation of patients who should \\ never be undergoing resuscitation because the \\ conversation hasn't happened early enough.' \\ Doctor 1: 'I think it's something we should be \\ doing more readily and earlier and trying to \\ normalise.' \\ Doctor 8: 'Juniors are the people who are \\ more constant on the ward ... the patients \\ and families have a good relationship with the \\ junior team.'
}

Theme B: Variation in specialty

Doctor 4: 'Stroke and elderly medicine are very on the ball ... it's fairly bread-and-butter for them it's a common occurrence.'

Doctor 6: 'In some specialties, it's just not as much of a consideration.'

Doctor 7: 'We need adequate clinical exposure and experience to make those decisions.

\section{Theme C: Further educational needs}

Doctor 3: 'Very much something that I have learnt on the job, watching my seniors do it ... you learn buzzwords and you learn ways to say things that people don't take offence to.'

Doctor 1: 'I think with the way the Foundation Programme is structured, with a variety of different training days across the first couple of years, it's certainly something that could be considered being put in within that curriculum.' the ReSPECT forms, which incorporate both ACP and DNACPR decisions, is therefore problematic for foundation doctors. Official guidance (version 3; released 16 September 2020) recommends full completion of the ReSPECT document. According to best practice, the conversation should be framed to elicit the patient's views on possible future treatment options. This involves full exploration of what constitutes an acceptable quality of life given their preferences, rather than a focus on the abstract CPR decision. ${ }^{6}$ Therefore, in consideration of patients and their families, a flowing conversation considering escalation of care in its various guises, ultimately considering DNACPR, may be more welcomed. ${ }^{6}$ These discussions are delegated to foundation doctors, therefore, they need support to be able to hold them in a format prioritised for the individual patient rather than their own competences.

\section{Education and developing clinical practice}

The Foundation Programme will be highly variable in terms of order of rotation and experiences within them. Theme $B$ revealed that care of the elderly departments were found to actively promote ACP, and consideration of resuscitation status was a regular part of the ward round. As such, opportunities to witness senior clinicians undertaking discussions were forthcoming. The encouragement and support of seniors were key to the foundation doctors developing the necessary skills to hold ACP conversations. However, research suggests senior support (from those who have minimal experience of the frail older population) was found to be lacking for junior doctors dealing with end-of-life care issues. ${ }^{7}$ Theme B highlights that ACP was not a routine consideration in the surgical specialties, although the rationale underpinning these findings cannot be explained by this small-scale study. The literature supports this assertion as ACP is not routinely included in the perioperative period leading to high-risk surgery. ${ }^{8}$ The impact of the variation in attitude towards ACP between specialties requires further exploration. From the foundation doctors' perspective (theme A), the complexity of decision making within surgical and some interventional specialties was a barrier to holding ACP discussions due to limited experience.

The approach of care of the elderly clinicians helps to develop confidence in foundation doctors which, on reflection, infers benefit to all hospital specialties. Furthermore, it may be presumed that exposure to oncology or palliative care medicine will offer similar benefit to care of the elderly rotations, yet that was not always described by our participants. On a case-by-case basis, the foundation doctors role did not facilitate witnessing senior clinicians undertake ACP, so this experiential learning opportunity was missed. It has been suggested that seniors underestimate the fear and apprehension felt by juniors having these conversations, so seniors do not consider routinely inviting juniors to observe them as a valuable learning tool. ${ }^{2}$ The Second Conversation intervention promotes embedding supported learning within daily practice and encourages observation, direct experience and reflection. ${ }^{2}$ The intervention was found to be effective on longerstay wards with frequent ACP; therefore, the authors acknowledge this may not be transferable to other environments. Additionally, our study suggests the availability of both informal teaching and observational learning was highly dependent on specialty, which makes adopting a similar workplace-based intervention across the foundation programme problematic. Foundation doctors recognised a need for the inclusion of formal teaching as described in theme C. Given the evident variation in clinical practice and within the Foundation Programme, both experiential and formal teaching is needed to promote the development of this essential clinical skill.

The foundation doctors interviewed felt less empowered to hold ACP discussions without explicit instruction from a senior, irrelevant of specialty; however, the variation noted was a specific barrier to raising ACP concerns. In addition, the most challenging times to have ACP discussions is when they are unanticipated, an emergency or within the out-of-hours setting. ${ }^{9}$ Anecdotally, it was on these occasions that the foundation doctors found themselves in situations with deteriorating patients, without senior presence on the ward and without detailed ACP. On occasion, there was conflict within the patient's management plan; this was attributed to inconsistent consultant lead (eg consultant of the week models) which could result in uncertainty and a feeling of unease as to the expected plan. It was unclear to the participants as to the remit of a foundation doctors in an emergency setting without the benefit of senior support. Further research is needed to ascertain the frequency and reasons behind these difficult situations.

\section{Future research and conclusion}

Foundation doctors are in a unique position of potentially facing challenging ACP discussions with minimal previous experience; therefore optimising the learning experience during the 
Foundation Programme is essential. The complexity of initiating ACP conversations is beyond the remit of most foundation doctors. However, a grey area exists between the reality experienced and the ideal scenario. Observational learning and the encouragement of seniors to facilitate foundation doctors witnessing ACP conversations may be beneficial in developing knowledge to extend ACP conversations beyond DNACPR. Although these softer skills can be developed through informal learning opportunities, the training for foundation doctors should be standardised to prioritise this skill given the evident variation. There is a need to further explore the perceived differences between medical and surgical specialties. Qualitative research is an appropriate method to study these differences and is well placed to investigate any biases present.

\section{References}

1 Heyland DK, Dodek P, Rocker G et al. What matters most in endof-life care: perceptions of seriously ill patients and their family members. CMAJ 2006;174:627-33.

2 Mathew R, Weil A, Sleeman K et al. The Second Conversation project: Improving training in end of life care communication among junior doctors. FHJ 2019;6:129.

3 Larson DG, Tobin DR. End-of-life conversations: evolving practice and theory. JAMA 2000;284:1573-8.
4 Fritz Z, Pitcher D, Hawkes C, Nolan J. Development of a national approach to resuscitation decisions: The Recommended Summary Plan for Emergency Care and Treatment (ReSPECT). Resuscitation 2016;106:733.

5 Bailey S, Cogel K. Talking about dying: How to begin honest conversations about what lies ahead. Royal College of Physicians, 2018. www.rcplondon.ac.uk/projects/outputs/talking-about-dyinghow-begin-honest-conversations-about-what-lies-ahead

6 Pitcher D, Fritz Z, Wang M, Spiller J. Emergency care and resuscitation plans. BMJ 2017;356:876.

7 Bharmal A, Morgan T, Kuhn I, Wee B, Barclay S. Palliative and endof-life care and junior doctors': a systematic review and narrative synthesis. BMJ Support Palliat Care 2019 [Epub ahead of print].

8 Blackwood D, Vindrola-Padros C, Mythen M, Walker D. Advancecare-planning and end-of-life discussions in the perioperative period: a review of healthcare professionals' knowledge, attitudes, and training. Br J Anaesth 2018;121:1138-47.

9 Hall C, Lugton J, Spiller JA, Carduff E. CPR decision-making conversations in the UK: An integrative review. BMJ Support Palliat Care 2019;9:1-11.

Address for correspondence: Miss Miriam Jassam, University of Leeds Medical School, Woodhouse Lane, Leeds LS2 9JT, UK.

Email: miriam.jassam@nhs.net

Twitter: @hels_chapman 